\title{
La responsabilidad del Estado colombiano frente a la emergencia carcelaria y penitenciaria por la COVID-19
}

\author{
The responsibility of the Colombian government \\ in the face of the prison and penitentiary emergency \\ due to COVID-19
}

\author{
Enán Arrieta-Burgos (D) \\ Doctor Summa cum laude en Filosofía \\ Universidad Pontificia Bolivariana \\ enan.arrieta@upb.edu.co
}

\author{
Andrés Felipe Duque-Pedroza \\ Doctor Summa cum laude en Derecho \\ Universidad Pontificia Bolivariana \\ andresf.duque@upb.edu.co
}

Hernán Vélez Vélez

Magíster en Derecho

Universidad Pontificia Bolivariana

hernan.velez@upb.edu.co 


\section{Resumen}

En este artículo se analizan los criterios que deben considerarse para evaluar la responsabilidad del Estado colombiano por las afectaciones que sufran, derivadas de la COVID-19, las personas privadas de la libertad (PPL). Así, en primer lugar, se estudia la emergencia sanitaria generada por la COVID-19 y sus efectos en el sistema punitivo colombiano. En segundo lugar, se describe la respuesta de las instituciones estatales en el marco del estado de cosas inconstitucional declarado por la Corte Constitucional. En tercer lugar, se analizan los principales desarrollos jurisprudenciales que, en materia contencioso administrativa, se han identificado en torno a la violación de los derechos de las PPL por causas imputables al Estado. Finalmente, se esbozan algunas conclusiones en torno a la posibilidad o no de adoptar criterios flexibles que permitan evaluar la responsabilidad del Estado colombiano frente a una situación inédita en la historia reciente.

\section{Palabras clave}

COVID-19; responsabilidad del Estado; falla en el servicio; estado de cosas inconstitucional; emergencia carcelaria y penitenciaria.

\section{Abstract}

This article analyzes the criteria considered on the evaluation of the responsibility of the Colombian government derived from COVID-19 on the people deprived of liberty effects suffer. Thus, in the first place, the health emergency generated by COVID-19 and its effects on the Colombian prisoner system is studied. Second, the response of the government that we describe in the framework of the unconstitutional ministry of affairs declared by the Constitutional Court. Third, the main jurisprudential developments in contentious-administrative matters. We identified and analyzed it regarding the violation of the rights of the people deprived of liberty due to causes attributable to the government. We consider some conclusions regarding the possibility of adopting flexible criteria. We evaluate the responsibility of the Colombian government in the face of an unprecedented situation in recent history.

\section{Keywords}

COVID-19; responsibility of the government; a failure in service; the unconstitutional ministry of affairs; prison and prisoner emergency.

\footnotetext{
Cómo citar este artículo:

Arrieta-Burgos, E., Duque-Pedroza, A., \& Vélez Vélez, H. (2021). La responsabilidad del Estado colombiano frente a la emergencia carcelaria y penitenciaria por la COVID-19. Revista de la Facultad de Derecho y Ciencias Políticas, 51 (134), pp. 177 - 211.

doi: https://doi.org/10.18566/rfdcp.v51n134.a08

Recibido: 9 de julio de 2020

Aprobado: 23 de noviembre de 2020
} 


\section{Introducción}

Además de los lineamientos generales trazados por la Constitución Política de 1991, el régimen punitivo en Colombia se encuentra previsto en el Código Penal (Ley 599 de 2000), en el Código de Procedimiento Penal (Ley 906 de 2004) y en el Código Penitenciario y Carcelario (leyes 65 de 1993 y 1709 de 2014). Particularmente, la ejecución de la pena se regula a través de un cuerpo de decretos, resoluciones, directivas y reglamentos particulares de los centros penitenciarios y carcelarios, lo cual pone en evidencia el importante rol que juega el Poder Ejecutivo en la gestión del castigo.

Con ocasión de la crisis generada por la pandemia de la COVID-19, los estados se han visto en la necesidad de adaptar su marco regulatorio para responder a una situación extraordinaria que carece de antecedentes en la historia reciente. El contexto penitenciario y carcelario no ha sido ajeno a esta realidad y, en el contexto global, los gobiernos han adoptado medidas, en las distintas fases de criminalización, orientadas a conjurar la crisis y evitar la extensión de sus efectos. Para el caso de Colombia, la adecuación, idoneidad, necesidad y proporcionalidad de estas medidas serán, finalmente, objeto de evaluación por parte de la Corte Constitucional y de los jueces administrativos que, en el marco de sus competencias, deban resolver eventuales litigios que se presenten a propósito de la responsabilidad del Estado colombiano por las afectaciones que sufran las personas privadas de la libertad (en adelante, PPL) a raíz de la COVID-19.

Bajo este horizonte, el presente artículo tiene por objeto analizar los factores que inciden en la responsabilidad del Estado colombiano frente a la emergencia carcelaria y penitenciaria por la COVID-19. La pregunta de investigación que guía nuestro análisis es: ¿qué criterios deben tenerse en cuenta para evaluar la responsabilidad del Estado colombiano por las afectaciones que sufran, derivadas de la COVID-19, las personas privadas de la libertad? Esta pregunta es relevante debido al carácter severo y multidimensional de las afectaciones derivadas del coronavirus y los factores de riesgo asociados a las prisiones ${ }^{1}$. Así, aunque algunos efectos en el largo plazo son desconocidos, es claro que la COVID-19 puede desencadenar en la muerte de la persona contagiada, riesgo que aumenta por la edad y algunas comorbilidades asociadas (Zhou et al., 2020).

\footnotetext{
1 Una recopilación de los principales aportes académicos sobre los efectos de la COVID-19 en las prisiones en el contexto mundial puede verse en el World Prison Brief del Institute for Crime \& Justice Policy Research de la Birkbeck University of London (2020).
} 
Asimismo, la literatura especializada ha identificado, como consecuencia de esta enfermedad, diferentes secuelas respiratorias y cardiovasculares en los pacientes infectados (Richardson et al., 2020). En el contexto de las prisiones, se ha llamado la atención sobre las consecuencias de esta afección en la salud mental de las PPL (Liebrenz, Bhugra, Buadze y Schleifer, 2020).

Para responder al problema de investigación planteado, sostendremos la siguiente hipótesis: por la naturaleza extraordinaria de la crisis y el régimen obligacional aplicable, deben emplearse criterios flexibles que permitan evaluar la responsabilidad del Estado colombiano en cada caso concreto. Para fundamentar lo anterior, en un primer momento se analizará la emergencia sanitaria generada por la COVID-19 y sus efectos en el sistema punitivo colombiano. En segundo lugar, se describirá la respuesta de las instituciones estatales en el marco del estado de cosas inconstitucional declarado por la Corte Constitucional. En tercer lugar, se estudiarán los principales desarrollos jurisprudenciales que, en materia contencioso administrativa, se han identificado en torno a la violación de los derechos de las PPL por causas imputables al Estado. Finalmente, esbozaremos algunas conclusiones, problematizando el alcance de los criterios que deben tenerse en cuenta para determinar la responsabilidad del Estado colombiano frente a la emergencia carcelaria y penitenciaria por la COVID-19.

Para cerrar esta introducción, es necesario advertir que este artículo es resultado de una investigación que se inscribe bajo el paradigma complejo (Morin y Le Moigne, 1999) y que se circunscribe a diferentes proyectos de investigación en los que participan los autores ${ }^{2}$. Por ende, para la operacionalización de la hipótesis se asumió un enfoque investigativo mixto (Bryman, 2012), que conjuga métodos y materiales propios de las investigaciones cualitativas y cuantitativas. Desde el punto de vista normativo, se emplea el método hermenéutico como referente principal del enfoque cualitativo (Heidegger, 1998; Grondin, 2006). Así, para determinar los límites de sentido de las fuentes legales y constitucionales, se puso a prueba un ejercicio de hermenéutica analógica entre las disposiciones normativas, los pronunciamientos jurisprudenciales y la literatura jurídica especializada (Beuchot, 2000). Esto se concreta en un análisis de corte dogmático, categoría empleada por Guastini (2011), Prieto

2 Este artículo es resultado de los proyectos de investigación "La responsabilidad civil en Colombia desde su dimensión preventiva: hacia un intento de fundamentación a partir de una teoría sociojurídica" (proyecto de investigación doctoral, Universidad Santo Tomás) y "La sociedad punitiva III: acoplamientos e irrigaciones mutuas entre las ciencias penales, sociales y humanas" (Universidad Pontificia Bolivariana). 
(2005) y Courtis (2006) para describir las investigaciones jurídicas en estricto sentido. Finalmente, desde el punto de vista empírico, se emplea el método correlacional para estudiar los datos estadísticos contenidos en los registros administrativos sobre PPL y la COVID-19 (Johnson, 2001; Curtis, Comiskey y Dempsey, 2016).

\section{Emergencia sanitaria por COVID-19 y sistema punitivo en Colombia}

Antes de describir y valorar la actual situación penitenciaria y carcelaria en Colombia, de modo que desde ella podamos extraer relaciones con posibles juicios de responsabilidad del Estado, expliquemos dos premisas fundamentales que le sirven de soporte al sistema punitivo colombiano.

En primer lugar, como ocurre con todo el poder punitivo, en la fase de ejecución, los límites al ejercicio de la potestad sancionadora del Estado constituyen, a su vez, las condiciones que hacen posible su ejercicio. Es decir, la condición de su existencia es la misma de su legitimidad. Así, solo hay derecho penal si su ejercicio está sujeto a límites. Sin límites, este derecho deja de ser tal para convertirse en un simple uso irracional de la fuerza vengativa. En segundo lugar, aun cuando son varias las finalidades que se quieren alcanzar con la imposición y ejecución de la pena, aquella que, por excelencia, se privilegia en el sistema penal colombiano, es la resocialización del condenado. Y es en la fase de ejecución, en comparación con las demás etapas del ejercicio del poder punitivo, en donde, con mayor razón, se deben generar ambientes propicios para generar la resocialización del condenado en atención a su dignidad humana.

En cuanto a los límites, dos postulados se encuentran directamente vinculados con la ejecución de la pena, como señalan Solano, Duque-Pedroza, Díez, Arrieta-Burgos, Estrada y Monsalve (2019). En primer lugar, y por virtud del principio de legalidad, establecer que la ejecución de la pena no debe comportar una punición adicional a aquella establecida en la ley para el hecho por el cual el sujeto fue condenado. Esto es, que la restricción de la libertad en prisión no debe comportar afectaciones que desborden el ámbito de la libertad de locomoción y derechos conexos (intimidad, asociación, reunión, trabajo y unidad familiar). De allí que, puniciones adicionales a la restricción de la libertad, constituirán un exceso en el ejercicio del poder punitivo. En 
este sentido, por ejemplo, no será posible ni legítimo afectar los derechos fundamentales a la salud o a la alimentación de los condenados solo por el hecho de pesar sobre ellos una restricción a la libertad en centro carcelario. En segundo lugar, quisiéramos resaltar el postulado del respeto por la dignidad de la persona humana. Desde esta perspectiva, el derecho a la dignidad humana, junto con todos sus postulados derivados en materia de derechos fundamentales, no se pierde por el hecho de que una persona se encuentre privada de su libertad (Artículo 5, Código Penitenciario y Carcelario). La dignidad, así concebida, constituye el principal marco referencial de toda actuación del Estado, incluyendo, por supuesto, la persecución del delito en su fase de ejecución de las consecuencias jurídicas.

El cambio de la simple retribución del mal generado con el delito a un sistema punitivo que, además, incluya otras finalidades resocializadoras en la imposición de la pena, se fundamenta en el ideal ilustrado de humanizar el castigo penal a través de la prisión (Foucault, 1975; 2013; 2015; Arrieta-Burgos y Duque-Pedroza, 2018). La humanización de la pena es un deber del Estado, en tanto que es este quien, a través de una especial relación de sujeción con las $\mathrm{PPL}^{3}$, debe diseñar todos los programas, herramientas y condiciones que, por un lado, impidan la doble punición que acabamos de mencionar y, por el

3 La especial relación de sujeción en materia carcelaria ha sido claramente explicada por la Corte Constitucional en varias sentencias. Por ejemplo, en sentencia T-1190 de 2003, expresó: "Las relaciones de especial sujeción implican (i) la subordinación de una parte (el recluso), a la otra (el Estado); (ii) esta subordinación se concreta en el sometimiento del interno a un régimen jurídico especial (controles disciplinarios y administrativos especiales y posibilidad de limitar el ejercicio de derechos, incluso fundamentales); (iii) este régimen, en cuanto al ejercicio de la potestad disciplinaria especial y a la limitación de los derechos fundamentales, debe estar autorizado por la Constitución y la ley; (iv) la finalidad del ejercicio de la potestad disciplinaria y de la limitación de los derechos fundamentales, es la de garantizar los medios para el ejercicio de los demás derechos de los internos (mediante medidas dirigidas a garantizar disciplina, seguridad y salubridad) y lograr el cometido principal de la pena (la resocialización); (v) como consecuencia de la subordinación, surgen ciertos derechos especiales (relacionados con las condiciones materiales de existencia: alimentación, habitación, servicios públicos) en cabeza de los reclusos, los cuales deben ser especialmente garantizados por el Estado; (vi) simultáneamente, el Estado debe garantizar, de manera especial, el principio de eficacia de los derechos fundamentales de los reclusos (sobre todo con el desarrollo de conductas activas)... En este orden de ideas, queda claro que, en relación con las personas privadas de la libertad, las autoridades públicas (i) pueden limitar el ejercicio de algunos derechos fundamentales (intimidad, reunión, trabajo, educación, unidad familiar); (ii) la imposibilidad de limitar el ejercicio de determinados derechos fundamentales (vida, dignidad humana, debido proceso, habeas data, entre otros); y (iii) el deber positivo, en cabeza del Estado, de asegurar el goce efectivo de los fundamentales, en la parte que no sea objeto de limitación cuando la misma proceda, y en su integridad frente a los demás, debido a la especial situación de indefensión o de debilidad manifiesta en la que se encuentran los reclusos". 
otro, que faciliten mecanismos de reintegración del condenado a la sociedad ${ }^{4}$. En últimas, se le quiere asignar a la pena alguna utilidad real, sin desconocer el mal que supone su imposición. De allí, por ejemplo, surgen, con el castigo moderno, los programas de enseñanza, trabajo y estudio que se ofrecen, para efectos del cómputo de la redención de la pena, en los centros de reclusión, con miras a facilitar escenarios de reinserción social una vez purgada la pena (Arrieta-Burgos, 2017).

Pues bien, después de este panorama normativo, es necesario diagnosticar cuál es la situación actual de Colombia en materia penitenciaria y carcelaria y detallar cómo se ha visto afectada como consecuencia de la COVID-19. En síntesis, es indispensable evaluar cómo ha sido la respuesta del Estado, antes y después de la pandemia COVID-19, en el tratamiento penitenciario y carcelario. La respuesta a estas preguntas exige un acercamiento empírico a la actual situación penitenciaria y carcelaria del país, por medio de un comparativo con lo que ha pasado en años anteriores. Así, resulta particularmente relevante comparar los indicadores penitenciarios y carcelarios a marzo de 2020, mes en el que se declara la pandemia, y los últimos datos disponibles a octubre de 2020.

Gráfico 1. Evolución del porcentaje de hacinamiento (1998-2020)

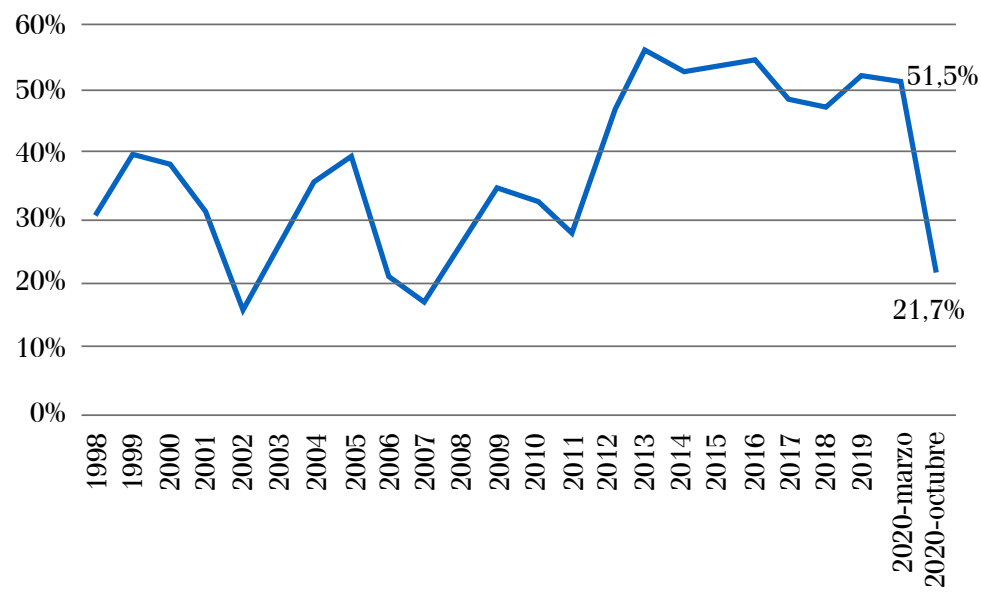

Fuente: elaboración propia a partir de datos del INPEC (2020b). Datos con corte a octubre de 2020.

4 En un reciente escrito de Duque y Solano (2020) se analizó la compatibilidad del modelo funcionalista sistémico (en auge en la dogmática penal contemporánea) con las finalidades de reintegración social al condenado que se buscan en Colombia. 
El porcentaje actual de hacinamiento carcelario sigue siendo alarmante. Sin embargo, después de la emergencia sanitaria y, particularmente, a partir de la expedición del Decreto 546 de 2020, que directamente se dirigía a las PPL, se logró un descenso en el hacinamiento bastante considerable, cercano a los 30 puntos porcentuales (de 51,5\% en marzo de 2020 a 21,7 \% en octubre de 2020). Esto es interesante, pues si bien, hasta noviembre de 2020, por el Decreto 546 de 2020, solo habían recuperado la libertad 1151 PPL (El Espectador, 2020b), la emergencia también ha logrado que solo se generen mínimas y excepcionales nuevas restricciones a la libertad, al igual que ha fomentado que se implementen mecanismos ordinarios para facilitar la excarcelación de las PPL, al punto de que, a través de estos mecanismos ordinarios, más de 19 mil reclusos han recuperado su libertad (El Espectador, 2020b). De esta manera, es de rescatar que, en tan solo pocos meses y a raíz de la pandemia, el indicador de hacinamiento se redujo a valores similares a los de 2008. Ello demuestra, en parte, que el Estado colombiano no ha sido indiferente a la emergencia.

Ahora bien, visto el Gráfico 1 de una forma global, salvo cuatro períodos claramente determinados -(i) de 1999 al 2002; (ii) del 2005 al 2007; (iii) del 2009 al 2011 y (iv) del 2015 al 2018-, los demás dan cuenta de una tendencia al alza en materia de hacinamiento. Los períodos de descenso que se mencionan tienen como explicación, a modo de correlación, bien el cumplimiento de algunas órdenes concretas emitidas en los estados de cosas inconstitucionales, como ocurre con el primer período, bien por reformas o inclusiones legislativas que han restringido, casi siempre de forma parcial, el uso de medidas restrictivas a la libertad. Así, por ejemplo, el segundo período de descenso puede obedecer a la implementación del Código de Procedimiento Penal, descenso que se mantuvo hasta el 2007, cuando entró a regir la Ley 1142. Con esta, al aumentar los ámbitos de intervención punitiva, subió también el hacinamiento carcelario. Lo mismo puede decirse, solo para referenciar una última correlación, del descenso que se manifiesta desde el 2015, producto de la implementación de la Ley 1760 , que trajo consigo mayores cargas a la Fiscalía para la imposición de medidas de aseguramiento privativas de la libertad.

Ahora bien, al margen de estas correlaciones, lo cierto es que alto porcentaje de hacinamiento actual obedece, entre otras razones, a la expansión de los ámbitos de aplicación del derecho penal, unido a la reducción o limitación de subrogados o posibilidades distintas a la reclusión carcelaria. Es así como, aun cuando en valores absolutos el número de sindicados y de condenados ha aumentado, en valores relativos tenemos que la tasa de PPL sin condena ha venido reduciéndose. 
Gráfico 2. Número de sindicados / Número de condenados (1998-2020)

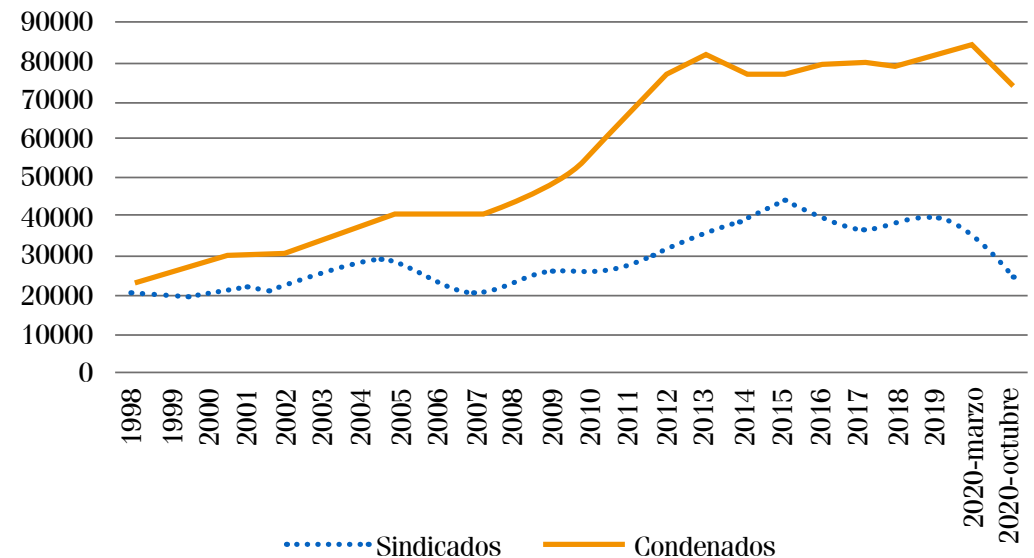

Para los años 1998 a 2019 se toma el valor promedio para la respectiva anualidad.

Fuente: elaboración propia a partir de datos del INPEC (2020d). Datos con corte a octubre de 2020.

Gráfico 3. Distribución porcentual de sindicados y condenados sobre el total de PPL (1998-2020)

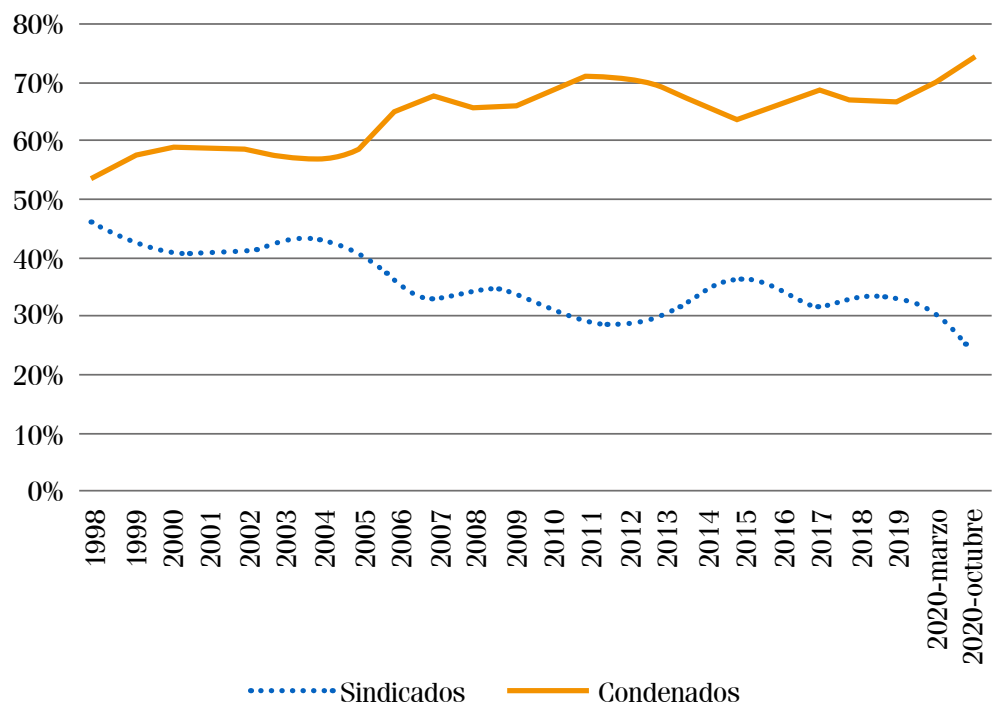

Para los años 1998 a 2019 se toma el valor promedio para la respectiva anualidad.

Fuente: elaboración propia a partir de datos del INPEC (2020d). Datos con corte a octubre de 2020. 
De la gráfica anterior puede concluirse que, si bien se le atribuye al sistema penal acusatorio colombiano (Ley 906 de 2004) una importante causa para el descenso porcentual en el número de sindicados, también puede encontrarse en este sistema una razón determinante para el aumento porcentual de condenados. Esto, pues se trata de un sistema que privilegia la terminación anticipada del proceso mediante mecanismos de justicia premial o negocial.

Ahora, si bien los porcentajes de hacinamiento han mejorado con ocasión de la pandemia, debe decirse que, por lo menos desde el segundo estado de cosas inconstitucional decretado en el 2013, han aumentado el número de sustitutos de la privación de la libertad intramural, como la prisión domiciliaria, así:

Gráfico 4. Número de PPL por lugar de cumplimiento de la medida (2013-2020)

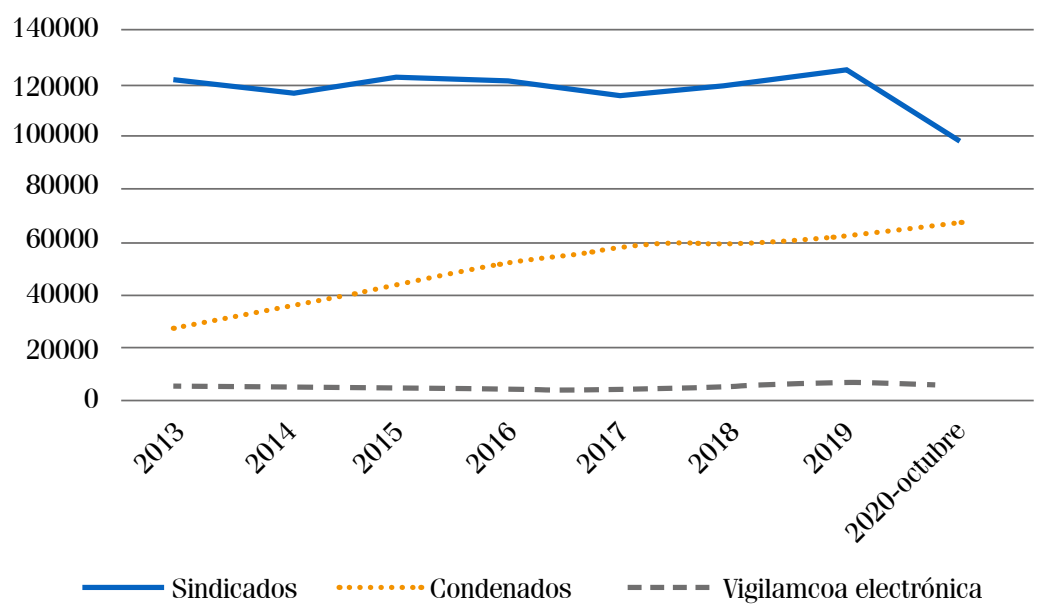

Fuente: elaboración propia a partir de datos del Ministerio de Justicia (2020d). Datos con corte a octubre de 2020.

En todo este panorama, el problema de hacinamiento empeora si, como lo indica el INPEC en sus estadísticas del 2020, el porcentaje de reincidencia en Colombia viene aumentando desde el 2015. Es decir, la finalidad resocializadora está, aún, lejos de alcanzarse si, como lo demuestran las cifras, actualmente el $18 \%$ de las PPL son reincidentes (INPEC, 2020b). En 2015, por ejemplo, cuando se expidió el tercer estado de cosas inconstitucionales en materia de prisiones en Colombia, el porcentaje de reincidencia era del $13 \%$ (INPEC, 2020b). Es decir, paradójicamente, a pesar de la crítica al sistema político 
criminal que se planteó en el 2015, se ha generado también un aumento en los niveles de reincidencia. Esto, por supuesto, no es un problema que tenga solo, como causa, una deficiencia en el sistema de ejecución de la pena, pues se trata de un problema multicausal y sistémico.

Gráfico 5. Número de reincidentes sobre el total de PPL (2015-2020)

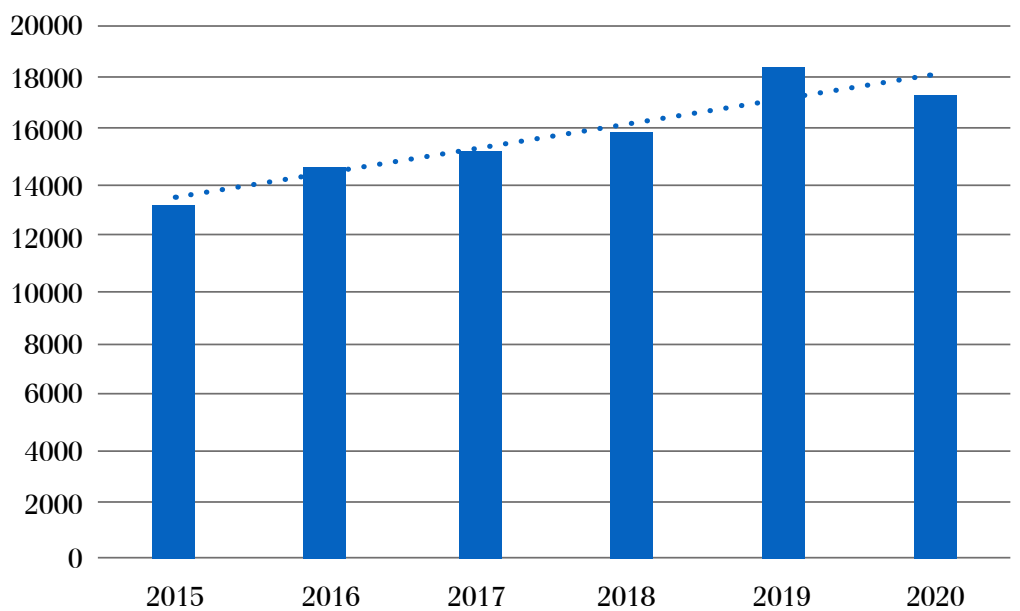

Fuente: elaboración propia a partir de datos del INPEC (2020e). Datos con corte a octubre de 2020.

Y es en medio de esta crisis donde se manifiestan los efectos de otra: la generada por la COVID-19. Las cifras que se han evidenciado demuestran que los graves problemas del sistema penitenciario y carcelario colombiano no son imputables a la pandemia, sino que se trata, pues, de "falencias estructurales" que operan como constantes en todos los centros punitivos de América Latina (Rodríguez, 1992; Carranza, 2009; Aguirre, 2009; Márquez-Estrada, 2013). Por supuesto, a los problemas ya existentes se les sumaron los generados por la COVID-19, toda vez que, en porcentajes tan elevados de hacinamiento y con las deficiencias de los sistemas de salud y sanitario de las prisiones colombianas (Ariza e Iturralde, 2011), era apenas lógico que la llegada del virus aumentaría considerablemente la crisis penitenciaria y carcelaria.

Sin embargo, aunque el hacinamiento aumenta las probabilidades de contagio de la COVID-19 entre las PPL, no es el único factor de riesgo asociado a los establecimientos de reclusión. Aunque es cierto que las condiciones de 
hacinamiento en América Latina tienen efectos especialmente severos en la incidencia y prevalencia de las infecciones por coronavirus en nuestras prisiones (Sociedad de Criminología Latinoamericana y Centro de Estudios Latinoamericanos sobre Inseguridad y Violencia UNTREF - CELIV, 2020), también lo es que las características infraestructurales y sanitarias inherentes a los establecimientos de reclusión, en todo el mundo, dificultan la implementación de medidas orientadas a evitar la propagación de la enfermedad (Jones y Tulloch, 2020).

Por esta razón, los establecimientos penitenciarios y carcelarios en el marco internacional se han convertido en puntos focales para la mitigación de la pandemia (Montoya-Barthelemy, Lee, Cundiff y Smith, 2020), puesto que en ellos concurren, inevitablemente, tres condiciones asociadas con una alta posibilidad de contagio: espacios cerrados, aglomerados y con poca ventilación.

Cuadro 1. Factores de riesgo asociados con la COVID-19 en prisiones colombianas

\begin{tabular}{|l|}
\hline Hacinamiento \\
\hline Entornos congregados y aglomerados (alimentación, estudio, aseo, trabajo, recreación, etc.) \\
\hline Falencias en la infraestructura sanitaria \\
\hline Ausencia de áreas de aislamiento \\
\hline Déficit de personal sanitario y asistencial \\
\hline Movilidad y rotación de guardianes, personal administrativo y PPL \\
\hline Comorbilidades de las PPL \\
\hline
\end{tabular}

Fuente: elaboración propia a partir de la información del INPEC (2020a).

Solo por ejemplificar -pues, cada uno de estos riesgos debe ser evaluado, en concreto, en cada establecimiento de reclusión-, tenemos que, según los informes estadísticos del INPEC (2020b) de noviembre de 2020, los establecimientos de las regiones noreste y norte poseen, respectivamente, indicadores de hacinamiento superiores al $48 \%$ y al $33 \%$. En estas condiciones, es materialmente imposible controlar los eventuales contagios a través medidas de aislamiento o distanciamiento social (físico), incluso, con independencia de la implementación de cualquier protocolo de bioseguridad. Es decir, todo el sistema penitenciario colombiano representa, en sí mismo, un alto riesgo para el contagio por el virus. 
Frente a estos riesgos se han formulado distintas recomendaciones a los gobiernos para que adopten acciones concretas, en términos de políticas públicas y gestión del castigo (Wurcel et al., 2020). En Colombia, para hacerle frente a esta situación, se abrieron dos campos de acción: uno sanitario, para la gestión de la pandemia en los centros de reclusión, y otro políticocriminal orientado a reducir los indicadores de hacinamiento. En primer lugar, el Ministerio de Salud y Protección Social (2020a), mediante la Resolución 843 del 26 de mayo de 2020, adoptó el Protocolo de bioseguridad para el manejo y control del riesgo del coronavirus - COVID-19 en establecimientos penitenciarios y carcelarios, complementando los Lineamientos para control, prevención y manejo de casos por COVID-19 para la población privada de la libertad-PPL en Colombia, expedidos en abril (Ministerio de Salud y Protección Social, 2020b). En segundo lugar, el Gobierno nacional expidió el Decreto Legislativo 546 del 14 de abril de 2020. Tal y como se expresa en esta regulación, su finalidad es evitar el contagio de la COVID-19, su propagación y las consecuencias que de ello se deriven. Para lograr este cometido, según se expresa, este decreto adopta medidas para sustituir la pena de prisión y la medida de aseguramiento de detención preventiva en establecimientos penitenciarios y carcelarios por la prisión domiciliaria, y la detención domiciliaria transitorias en el lugar de residencia a personas que se encuentran en situación de mayor vulnerabilidad frente a la COVID-19. Es importante anotar que, mediante la Sentencia C-255 de 2020, la Corte Constitucional respaldó, en términos generales, la validez constitucional de este decreto.

En ese sentido, el decreto identifica a las siguientes PPL para ser beneficiarias de las medidas transitorias de libertad domiciliaria: a) Personas que hayan cumplido 60 años de edad; b) madre gestante o con hijo menor de tres (3) años de edad, dentro de los establecimientos penitenciarios; c) personas en situación de internamiento carcelario que padezcan ciertas enfermedades que agraven su riesgo de contagio; d) personas con movilidad reducida por discapacidad debidamente acreditada; e) personas condenadas o que se encuentren con medida de aseguramiento de detención preventiva en establecimiento penitenciario y carcelario por delitos culposos; f) condenados a penas privativas de la libertad de hasta cinco (5) años de prisión; g) quienes hayan cumplido el cuarenta por ciento (40 \%) de la pena privativa de la libertad en establecimiento penitenciario, atendidas las respectivas redenciones a que se tiene derecho. La Corte Constitucional, en la Sentencia C-255 de 2020, precisó que estas personas, beneficiarias de las medidas transitorias de libertad domiciliaria, aunque deben reportarse ante las autoridades una vez finalice el plazo de estas medidas, no pueden ser nuevamente recluidas si en el centro de privación de la libertad se 
presenta un brote de COVID-19, a menos de que el INPEC pueda garantizarles un sitio alternativo de reclusión. Si esto último no es posible, la autoridad judicial podrá prorrogar la medida transitoria.

Asimismo, el Decreto 546 de 2020 expresa que las personas que hayan sido diagnosticadas por la enfermedad COVID-19 dentro de los establecimientos penitenciarios y carcelarios serán trasladadas a los lugares que resulten más aptos para el tratamiento o a las instituciones de salud que se disponga por parte de las autoridades competentes.

Ahora, si bien parece que el grupo de personas seleccionadas para la aplicación del decreto es amplio y que la motivación, en términos de proporcionalidad, obedeció a una debida ponderación que privilegiaba la salud y la vida, el mismo decreto consagró una extensa lista de exclusiones para el otorgamiento de la libertad transitoria. Así, para evitar una especie de excarcelación masiva, el Gobierno colombiano estableció un régimen de exclusiones que juzgó idóneo, necesario y proporcional para mantener la seguridad ciudadana. Este régimen de exclusiones consagra más de $\mathbf{7 0}$ supuestos por los que no procede el beneficio, ni aun tratándose de PPL vulnerables debido a su edad o comorbilidades asociadas. Esta consideración es importante, porque el Tribunal Constitucional rechazó expresamente, en la Sentencia C-255 de 2020, las solicitudes que, desde la academia, se habían formulado para que el Decreto 546 de 2020 fuese declarado inconstitucional por la ingente cantidad de exclusiones. Así, la Corte Constitucional estimó que estas exclusiones eran razonables y proporcionales a la luz de la Carta Magna.

De este régimen de exclusiones es posible inferir algunas conclusiones. En primer lugar, en general, se excluyeron los delitos respecto de los cuales, ordinariamente, procede la privación de la libertad en establecimiento carcelario. Es decir, un número significativo de personas privadas de la libertad quedaron agrupadas en las mismas exclusiones del decreto. En segundo lugar, en algunos casos, aunque parezca extraño, el régimen excepcional de libertad que se deduce del decreto tiene más restricciones que el régimen ordinario de libertad que se deduce de las leyes 599 de 200 y 906 de 2004. En tercer lugar, dentro de las exclusiones se encuentran los delitos relacionados con el tráfico y porte de estupefacientes, delitos que representan un muy amplio grupo de PPL. Identificamos en estas consideraciones solo este grupo de delitos, pues son aquellos que, política criminalmente, y por razones de salud pública, sustentan más posiciones críticas en cuanto a la necesidad de la privación de la libertad (Garland, 1987; 2015; Metall y Youngers, 2010). 
Además de lo mencionado, algunos de los grupos poblacionales identificados en el decreto como sensibles a factores de riesgo, son un número menor en comparación con el total de PPL. Veamos, por ejemplo, a octubre de 2020, el número de los PPL por rango etario y aquel relativo a las madres gestantes y en estado lactante.

Tabla 1. Rango etario de las PPL en establecimiento intramural

\begin{tabular}{|c|c|c|c|c|c|c|}
\hline \multirow{2}{*}{ Rango de edad } & \multicolumn{2}{|c|}{ Hombres } & \multicolumn{2}{c|}{ Mujeres } & \multicolumn{2}{c|}{ PPL intramuros } \\
\cline { 2 - 7 } & PPL & Participación & PPL & Participación & Total & Participación \\
\hline $18-24$ & 11823 & $12,9 \%$ & 847 & $11,8 \%$ & 12670 & $12,9 \%$ \\
\hline $25-29$ & 19627 & $21,4 \%$ & 1311 & $20,2 \%$ & 20938 & $21,3 \%$ \\
\hline $30-34$ & 16535 & $18,1 \%$ & 1121 & $16,8 \%$ & 17656 & $18,0 \%$ \\
\hline $35-39$ & 13753 & $15,0 \%$ & 1082 & $16,2 \%$ & 14835 & $15,1 \%$ \\
\hline $40-44$ & 10006 & $10,9 \%$ & 806 & $12,3 \%$ & 10812 & $11 \%$ \\
\hline $45-49$ & 6944 & $7,6 \%$ & 583 & $8,9 \%$ & 7527 & $7,7 \%$ \\
\hline $50-54$ & 4933 & $5,4 \%$ & 381 & $5,9 \%$ & 5314 & $5,4 \%$ \\
\hline $55-59$ & 3465 & $3,8 \%$ & 259 & $4,1 \%$ & 3724 & $3,8 \%$ \\
\hline $\mathbf{6 0 - 6 4}$ & $\mathbf{2 1 6 6}$ & $\mathbf{2 , 4} \%$ & $\mathbf{1 4 8}$ & $\mathbf{2 , 5} \%$ & $\mathbf{2 3 1 4}$ & $\mathbf{2 , 4} \%$ \\
\hline $\mathbf{6 5}-69$ & $\mathbf{1 2 7 8}$ & $\mathbf{1 , 4} \%$ & $\mathbf{6 2}$ & $\mathbf{1} \%$ & $\mathbf{1 3 4 0}$ & $\mathbf{1 , 4} \%$ \\
\hline$>\mathbf{7 0}$ & $\mathbf{1 0 1 6}$ & $\mathbf{1 , 1} \%$ & $\mathbf{2 6}$ & $\mathbf{0 , 5} \%$ & $\mathbf{1 0 4 2}$ & $\mathbf{1 , 1} \%$ \\
\hline Total & 91546 & $100 \%$ & 6626 & $100 \%$ & 98172 & $100 \%$ \\
\hline Participación & & $93,2 \%$ & & $6,8 \%$ & & $100 \%$ \\
\hline
\end{tabular}

Fuente: INPEC (2020e). Datos con corte a octubre de 2020.

Se identifica, en la gráfica, que el número de personas mayores de 60 años privadas de la libertad es muy bajo en comparación con grupos etarios inferiores a los 44 años. La edad es un factor de riesgo evidente asociado a la epidemia por COVID-19, tal y como lo ha afirmado la Organización Mundial de la Salud (2020). 
Tabla 2. Mujeres PPL gestantes y lactantes

\begin{tabular}{|l|c|c|}
\hline \multicolumn{1}{|c|}{ Condición } & Total & Participación \\
\hline Mujeres gestantes & 52 & $0,6 \%$ \\
\hline Mujeres lactantes & 11 & $0,1 \%$ \\
\hline
\end{tabular}

Fuente: elaboración propia a partir de la información del INPEC (2020e). Datos con corte a octubre de 2020.

De la misma manera, el grupo poblacional relativo a las mujeres en estado de embarazo o lactancia no superaba, a octubre de 2020, el 0,6 \% del total de la poblado PPL ${ }^{5}$.

Ahora bien, aunque las cifras son dinámicas, al 17 de noviembre de 2020, de acuerdo con datos del INPEC (2020c), en 47 establecimientos de reclusión había casos confirmados como positivos para COVID-19. De los 844 casos activos a dicha fecha, 755 correspondían a PPL, y el resto, a personal administrativo 0 de custodia y vigilancia (INPEC, 2020c). En el histórico de casos acumulados, con corte al 17 de noviembre de 2020, tenemos que 18380 personas se habían recuperado de COVID-19, de las cuales, 17002 correspondían a PPL. Lo anterior, teniendo en cuenta que el primer caso de contagio se reportó en la cárcel de Villavicencio en abril de 2020, y el pico de contagios se alcanzó para finales de junio, con más de 3200 casos activos, principalmente en Bogotá, Villavicencio e Ibagué (El Espectador, 2020b). En lo relacionado con los decesos, a noviembre de 2020, 69 PPL y 9 funcionarios del INPEC habían fallecido como consecuencia del COVID-19 (El Espectador, 2020b).

De estas cifras pueden extraerse algunas conclusiones. En primer lugar, las condiciones inherentes al encierro aceleran la curva de contagios en los centros carcelarios y penitenciarios en donde se ha detectado la COVID-19 (EI Espectador, 2020b). Los casos de Villavicencio, Leticia, Cali y Cartagena son un claro ejemplo de ello (El Espectador, 2020a). En Villavicencio, al 12 de junio de 2020, de sus 1700 internos y 300 funcionarios del INPEC, 886 habían contraído la enfermedad (El Espectador, 2020b). En segundo lugar, si bien el número de PPL contagiadas es alarmante, es necesario anotar que la proporción de

$5 \quad$ Las consecuencias negativas de la COVID-19 en mujeres embarazo han sido ya identificadas en los recientes estudios de Li et al. (2020) y Read y Wild (2020). 
fallecidos es menor al promedio nacional. en Colombia, con corte a octubre de 2020, sobre el total de personas confirmadas como positivas, el 2,9\% de los contagiados había fallecido como consecuencia directa del virus (Instituto Nacional de Salud, 2020). Frente a las PPL contagiadas, tenemos que este indicador sería cercano al 0,4 \% (69/17 757), aproximadamente. Si bien estas cifras son alarmantes, es importante tener en cuenta que, sobre el total de casos confirmados a la fecha, se ha recuperado el 88,5\% de las personas contagiadas y el 2,9 \% ha fallecido como consecuencia directa del virus. En tercer lugar, en estrecha relación con lo anterior, que los altos picos de contagio suelen descender en la misma proporción luego, por lo que se verifican significativos niveles de recuperación. En cuarto lugar, si bien los protocolos que se pueden implementar en las prisiones, pueden ser altamente ineficaces para prevenir el contagio, la gestión y vigilancia epidemiológica de la enfermedad se facilitan en los establecimientos de reclusión. Así, paradójicamente, por las condiciones inherentes al castigo, es más fácil identificar las cadenas de contagios.

Con este panorama, y ante los riesgos presentes en cualquier lugar cerrado que conglomere a un número significativo de personas, tenemos que el Decreto 546 de 2020 materializa un típico dilema constructivo simple (Copi, Cohen, y Rodych, 2018). Si se mantiene la actual política de libertad transitoria prevista en el Decreto 546 de 2020, es claro que ello no evitaría la extensión de los efectos de la pandemia en las prisiones. Ahora bien, si se adopta una política más marcada para promover la libertad transitoria y, por ejemplo, se suprimen algunas exclusiones, ello tampoco conseguiría evitar la propagación de la COVID-19 en los establecimientos de reclusión, porque el factor "aglomeración” en poco espacio no desaparece. Así, ante la magnitud de una pandemia, las decisiones que adopte el Ejecutivo no tienen efectos significativos en la incidencia y prevalencia de la enfermedad, pero sí, eventualmente, en la responsabilidad que podría serle imputable.

\section{El estado de cosas inconstitucional en el marco de la pandemia}

El hacinamiento y otros factores de riesgo especialmente relevantes para evaluar la respuesta estatal frente a la COVID-19 han sido objeto de análisis por parte de la Corte Constitucional, en el marco de los estados de cosas inconstitucionales (en adelante ECI) declarados en 1998, 2013 y 2015. Por lo anterior, es necesario realizar una aproximación al estudio de las causas y los 
efectos de los ECI que se han declarado a propósito del sistema penitenciario y carcelario, pues ello cobrará importancia en la determinación judicial de la responsabilidad del Estado colombiano por la gestión de la pandemia en los establecimientos de reclusión.

La figura del ECI le permite a la Corte Constitucional trascender su rol de "legislador negativo", para participar, directamente y en conjunto con el Poder Ejecutivo, en el proceso de diseño e implementación de políticas públicas (Yánez, 2008; Bernal, 2018; Arrieta-Burgos, 2019). Así las cosas, en materia penitenciaria y carcelaria se ha declarado el ECI mediante las sentencias T-153 de 1998, T-388 de 2013 y T-762 de 2015. Cada una de estas providencias parte de un diagnóstico y define una serie de medidas judiciales que conviene contrastar con la actual emergencia ocasionada por la COVID-19.

En la Sentencia T-153 de 1998, la Corte Constitucional ordenó nueve medidas concretas para conjurar la crisis que, en ese entonces, se originaba en problemas presupuestales y de infraestructura (Ariza, 2000). Por lo anterior, la principal solución, a juicio del Tribunal Constitucional, pasaba por: "Elaborar e implementar de un plan de construcción y refacción carcelaria tendente a garantizar a los reclusos condiciones de vida dignas en los penales", tarea esta a cargo del INPEC, el Ministerio de Justicia y el Departamento Nacional de Planeación.

A pesar de que la Corte Constitucional declaró superado el ECI de 1998, la mayor parte de las órdenes contenidas en la Sentencia T-153 fueron retomadas, con un nuevo enfoque, en la Sentencia T-388 de 2013, reiterada en la Sentencia T-762 de 2015. Con este nuevo rumbo, adoptado en 2013 y 2015 , se hizo énfasis en los problemas estructurales de la criminalización primaria y que están directamente vinculados con el diseño de la política criminal por parte del Legislador. La Corte Constitucional señaló, en esencia, que la política criminal colombiana no era respetuosa de los derechos humanos. De esta manera, aunque el Tribunal Constitucional no olvidó las condiciones materiales de existencia de las PPL, relegó a un segundo plano la discusión en torno a los factores presupuestales y de infraestructura atados a la crisis. La Corte Constitucional estimó que construir más centros de reclusión no atacaba la causa raíz de la crisis, por cuanto el hacinamiento y otras fallas operativas eran consecuencia de las decisiones políticocriminales adoptadas, principalmente, por el Congreso de la República.

En la Sentencia T-388 de 2013, el Tribunal Constitucional, ante las excarcelaciones que venían ordenando algunos jueces en el país como 
consecuencia de las deplorables condiciones en que se encontraban y encuentran nuestras prisiones, recordó una premisa que hoy, en tiempos pandémicos, resulta fundamental:

En un estado de cosas contrario al orden constitucional vigente, como el que atraviesan actualmente el sistema penitenciario y carcelario, las personas no adquieren un derecho constitucional subjetivo a ser excarceladas, sino a que se diseñen e implementen políticas criminales y carcelarias favorables a la libertad y sostenibles en el tiempo (Corte Constitucional, Sentencia T-388 de 2013).

En la misma línea de la Sentencia T-388 de 2013, en la Sentencia T-762 de 2015 la Corte Constitucional diagnosticó dos grupos de fallas que afectan el sistema penitenciario y carcelario en su conjunto. En primer lugar, a juicio del Tribunal Constitucional, la política criminal del Estado colombiano se adjetiva como "reactiva, populista, poco reflexiva, volátil, incoherente y subordinada a la política de seguridad” (Sentencia T-762 de 2015). En segundo lugar, la Corte Constitucional identificó falencias en las condiciones de reclusión de las PPL, denunciando:

(i) El hacinamiento; (ii) las condiciones sépticas e infrahumanas en las cuales se encuentran recluidos, debido principalmente a la deficiente infraestructura y sus efectos en las condiciones sanitarias; (iii) la falta de servicios asistenciales de salud; (iv) la imposibilidad de realizar actividades tendientes a su resocialización, dada la sobrepoblación carcelaria existente; (v) la falta de intimidad en el desarrollo de las visitas conyugales; y (vi) la reclusión conjunta e indistinta de las personas sujetas a medidas de aseguramiento privativas de la libertad y aquellas condenadas. (Corte Constitucional, Sentencia T-762 de 2015).

Pues bien, siguiendo la lectura crítica que proponen autores como Ariza (2013), a propósito del ECI, es necesario indicar, puntualmente de cara a la emergencia derivada por la COVID-19, algunos problemas relevantes. En primer lugar, a diferencia de lo ocurrido con otros ECI, la Corte Constitucional, sistemáticamente, renunció a un seguimiento directo y detallado de las órdenes decretadas en 1998, 2013 y 2015. La labor de seguimiento se les asignó a los jueces de instancia y, fundamentalmente a partir de 2015, a la Defensoría del Pueblo. En segundo lugar, al centrar su atención en las causas estructurales que están vinculadas con la criminalización primaria, el Tribunal Constitucional volvió, al estilo kelseniano, sobre su rol de legislador negativo. 
Bajo este nuevo enfoque, son las decisiones del Congreso de la República las que entran, prioritariamente, en la órbita del examen constitucional. Ahora bien, sin desconocer que, en efecto, la causa raíz de la emergencia penitenciaria y carcelaria en Colombia está directamente relacionada con las decisiones de política criminal, habría que preguntarse si ello ha supuesto un relajamiento en el control que el Tribunal Constitucional ha efectuado sobre la gestión administrativa a cargo del Gobierno nacional.

En todo caso, la sala especial de seguimiento a las sentencias T-388 de 2013 y T-762 de 2015 no se ha mostrado ajena a las implicaciones de la pandemia en las prisiones colombianas. Mediante auto del 24 de marzo de 2020, la Corte Constitucional le solicitó al Gobierno nacional información sobre los planes de contingencia adoptados para prevenir, detectar, contener y tratar la enfermedad COVID-19 en los establecimientos de reclusión. Igualmente, el Tribunal Constitucional requirió detalles sobre el proceso de articulación entre las autoridades penitenciarias, los entes territoriales y el sistema de salud, de cara a la respuesta frente a la emergencia sanitaria. Adicionalmente, la providencia ordena la caracterización de las PPL que poseen factores especiales de vulnerabilidad frente a la COVID-19. Asimismo, el Tribunal Constitucional llamó la atención para que las entidades del Ministerio Público refuercen la vigilancia en torno a la implementación de las estrategias de prevención y mitigación.

En respuesta a este auto, el Ministerio de Justicia (2020) remitió a la Corte Constitucional un informe en el que se detallan las guías, instructivos, lineamientos y directrices para la prevención, gestión y contención de los casos de la COVID-19 en los centros penitenciarios y carcelarios. En este informe se especifican las principales orientaciones emanadas del Gobierno nacional y que, sin lugar a duda, cobrarán relevancia en el análisis que los jueces deban hacer a la hora de evaluar la debida diligencia del Estado colombiano en la respuesta a la crisis.

Para cerrar esta segunda sección, vale la pena destacar que la COVID-19 ha exaltado la necesidad de gestionar los aspectos coyunturales de la crisis penitenciaria y carcelaria sin perder de vista sus causas estructurales. Sobre todo, cuando se está en presencia de crisis permanentes que han sido naturalizadas, es importante que el Estado se ocupe de medidas concretas que, si bien pueden ser coyunturales (infraestructura, por ejemplo), pueden tener más efectos prácticos que las preocupaciones generales que tiene por objeto la estructura misma de los problemas. 


\section{La responsabilidad patrimonial del Estado colombiano en la atención de la crisis}

La regla primordial y general sobre la responsabilidad patrimonial del Estado colombiano, desde 1991, viene dada por la disposición normativa prevista en el Artículo 90 de la Constitución. En términos generales, el Estado responde patrimonialmente por las actuaciones $\mathrm{u}$ omisiones de sus agentes, siempre que estas causen un daño antijurídico, es decir, una afectación que una persona no tenga por qué soportar jurídicamente (Tamayo, 2018).

Frente a los daños que las PPL pueden llegar a sufrir en el interior de los centros carcelarios, el Consejo de Estado, en aras de determinar cómo se les aplica a ellas el Artículo 90 de la Constitución, a lo largo de varios años, ha generado una jurisprudencia que se puede denominar variable (Gómez y Arrieta-Burgos, 2018), por dos razones: en primer lugar, porque a veces ha optado por una responsabilidad subjetiva; y otras, por una responsabilidad objetiva. En segundo lugar, y de manera respectiva, en ciertos casos ha empleado como título de imputación la falla del servicio (en ocasiones probada; en otras, presunta) y en otros, el daño especial.

Siguiendo de cerca los planteamientos de Gómez y Arrieta-Burgos (2018) analicemos cómo ha sido el itinerario jurisprudencial de esta materia en el Consejo de Estado.

En 1991, el Consejo de Estado invocó expresamente la falla presunta en el servicio como título de imputación para los casos de las PPL y fijó una regla judicial que puede resumirse así: el Estado colombiano tiene siempre que cumplir con las obligaciones de proteger la vida, la salud y, en general, los bienes de las personas. Sin embargo, la contundencia de dicha obligación cambia según las circunstancias, que, para el caso concreto, son si se trata de una persona que esté o no recluida en prisión. Será más exigente el cumplimiento de la obligación si se trata de una PPL, a si se trata de una persona que no lo es:

Así, frente a las personas detenidas por la autoridad o sometidas a conscripción obligatoria o a instrucción militar, mientras permanezcan en los lugares de reclusión o en los centros de enseñanza, la administración debe responder por la vida e integridad de las mismas y devolverlas, luego 
de esa detención o instrucción, en condiciones de salud similares a las que tenían cuando ingresaron. (Consejo de Estado, Sentencia del 25 de octubre de 1991).

Aunque a lo largo de la sentencia citada se invoca el título de imputación de la falla del servicio, la lectura del anterior apartado permite intuir el deseo judicial del Consejo de Estado por inclinarse -como luego ocurrió- hacia un régimen objetivo. Esta afirmación se sustenta en el hecho del empleo de expresiones que permiten concluir que, en caso de estar recluida una persona, esta "debe" volver a la libertad en condiciones de salud parecidas a las que tenía cuando entró en prisión.

En efecto, dos años más tarde, exactamente en 1993, sin abandonar formalmente el sistema subjetivo de responsabilidad patrimonial basado en la falla del servicio, el Consejo de Estado trajo al ámbito de la responsabilidad extracontractual del Estado un sistema de clasificación de las obligaciones que es propio de la responsabilidad civil contractual (Hinestrosa, 2007), y que es aquel que las divide en obligaciones de medio y de resultado, para concluir que, en el caso de las PPL, el Estado tiene ciertas obligaciones de resultado. En concreto, el Consejo de Estado indicó, que devolver a la persona recluida a la libertad en las condiciones de salud en que fue recluida (salvo el deterioro normal de acuerdo con la ciencia médica), era una obligación de resultado (Consejo de Estado, Sentencia del 4 de noviembre de 1993). A nuestro juicio, en la citada sentencia existe un error jurídico, porque las obligaciones de resultado, en el ámbito contractual, generan, ante su incumplimiento dañino, la activación de un sistema de responsabilidad objetiva (Ospina, 2018) y no subjetivo, que es la esencia de la adecuada concepción de la falla del servicio, bien probada o presunta (Ruiz, 2013).

Ese viraje hacia la responsabilidad objetiva respecto de los posibles daños que pueden sufrir las PPL en el interior de los centros de reclusión tomó más fuerza entre los años 2004 y 2006, cuando se enfatizó en el concepto de relación especial de sujeción en que se encuentran las PPL en centros carcelarios, relación esta que nace de la ostensible limitación de libertades que implica estar dentro de estos sitios y que resulta suficiente razón para que el Estado colombiano garantice una especial protección a estas personas que, al estar recluidas, pierden muchas capacidades de autoprotección y autocuidado (Gómez y Arrieta-Burgos, 2018; Consejo de Estado, Sentencia del 20 de mayo de 2004; Sentencia del 24 de junio de 2004; Sentencia del 27 de abril de 2006). 
Para el 2008, esta corporación, motivada por los planteamientos del exconsejero Enrique Gil Botero, enfatiza en el concepto de relación especial de sujeción, para concluir, nuevamente, que el régimen aplicable a los posibles daños causados a las PPL en los centros carcelarios era un fenómeno jurídico de responsabilidad objetiva, donde el Estado ocupa una posición de ser garante sobre la vida, la salud y los bienes de estas personas (Consejo de Estado, Sentencia del 20 de febrero de 2008).

Episódicamente, la posición fijada en la sentencia anterior tuvo una postura contraria y posterior, ya que tan solo en el 2009, el Consejo de Estado, en una de sus sentencias, retornó a la falla del servicio:

[...] en desarrollo de las normas penitenciarias y de una cabal observación de las cargas impuestas a unos y otros, corresponderá al juzgador evaluar en cada caso, si el servicio carcelario funcionó o no adecuadamente y, por tanto, declarar o no la responsabilidad estatal como quiera que el defectuoso funcionamiento del servicio carcelario podría comprometer la responsabilidad de la administración por falla del servicio. (Consejo de Estado, Sentencia del 11 de febrero de 2009).

Decimos que la posición basada en las relaciones de especial sujeción fue episódicamente controvertida, porque en el 2010 se marcó una tendencia importante hacia esta, no solo empleándose como base para un régimen objetivo, sino, también, bajo un título especial de imputación que el Consejo de Estado ha llamado "daño especial”, de acuerdo con el cual se sostiene que, si bien el Estado no está cometiendo un acto ilícito, en todo caso su actuar genera cargas y daños que el ciudadano no tiene jurídicamente por qué sostener (Santofimio, 2003).

Fue así como en 2010, el Consejo de Estado, de la mano de los conceptos de relación de especial sujeción y de daño especial, sostuvo que las PPL se encuentran en tal grado de indefensión frente al Estado que lo justo es tratar la reparación de sus daños por vía de un régimen objetivo en el que ni siquiera es necesario hablar de obligaciones de resultado, porque ese tipo de obligaciones son tan solo una clasificación del derecho privado (Consejo de Estado, Sentencia del 9 de junio de 2010). A partir de ese entonces toma fuerza este tratamiento jurídico, sin perjuicio de ciertos sectores del Consejo de Estado por tratar de regresar, en años posteriores -como el 2013, 2014 y 2016- a la falla del servicio. 
Por tanto, para el 2016 -conforme se observa en la Sentencia del 25 de julio de ese año- el Consejo de Estado era consciente de que la línea jurisprudencial sobre daños sufridos por PPL dentro de los centros de reclusión era caótica, variada y sin sentencias estabilizadoras (López, 2011).

Asimismo, en Sentencia proferida el 18 de mayo del año 2017 ${ }^{6}$, el Consejo de Estado vuelve a hacer un recuento de cómo la responsabilidad por daños a las PPL se ha comportado en forma pendular. Es decir, a veces bajo un régimen subjetivo y otras veces bajo un régimen objetivo. Sin embargo, en esta providencia se observa que esta corporación, en dicho momento, era partidaria de justificar en cada caso concreto que el título de imputación era aplicable. En el caso de dicha sentencia, se optó por la falla en el servicio probada, pero esta falla, contrario a lo habitual, se fundamentó no solo en el incumplimiento probado de los deberes del INPEC, sino, también, en el concepto de relaciones de especial sujeción, el cual siempre ha solido ser un apoyo conceptual de la responsabilidad objetiva. Esta misma postura se ratificó en Sentencia del 2 de mayo de 2018.

Por su parte, en Sentencia del 2 de agosto de 2018, el Consejo de Estado optó, también, por aplicar la falla del servicio probada para resolver favorablemente a los actores un caso donde, por una atención en salud defectuosa y tardía, una persona perdió la oportunidad de recuperar o mejorar su salud, a pesar de que previamente el centro carcelario conocía de sus necesidades de salud y alimentarias. Se descartó, sí, que los defectos y las tardanzas del INPEC en llevar al recluso a los centros de salud y en proveer la medicina necesaria para sus patologías fueran la causa fehaciente de su muerte, pero ante esa duda causal, se condenó por pérdida del chance. Lo más relevante de esta providencia es que, con claridad, indicó que el Estado tiene unos deberes frente a la salud, la vida y la alimentación de sus reclusos, y que no acatarlos genera una falla en

6 En esta providencia se delimitó, conceptualmente, el ámbito de responsabilidad concerniente a las relaciones de especial sujeción: "[...] las llamadas relaciones especiales de sujeción, que de acuerdo con el precedente constitucional implican : (i) la subordinación de una parte (el recluso), a la otra (el Estado); (ii) el sometimiento del interno a un régimen jurídico especial (controles disciplinarios y administrativos especiales y posibilidad de limitar el ejercicio de derechos, incluso fundamentales); iii) que la limitación de dichos derechos se encuentre autorizada por la por la Constitución y la ley ; (iv) que la limitación de los derechos fundamentales se lleve a cabo con la finalidad de garantizar los demás derechos de los internos (mediante medidas dirigidas a garantizar disciplina, seguridad y salubridad) y lograr el cometido principal de la pena (la resocialización); (v) que como consecuencia de la subordinación surgen ciertos derechos especiales (relacionados con las condiciones materiales de existencia: alimentación, habitación, servicios públicos, salud) en cabeza de los reclusos, los cuales deben ser especialmente garantizados por el Estado; y finalmente (vi), que simultáneamente surge para el Estado el deber de garantizar de manera especial el principio de eficacia de los derechos fundamentales de los reclusos (sobre todo con el desarrollo de conductas activas)" (Consejo de Estado, Sentencia del 18 de mayo de 2017). 
el servicio, la cual, en el caso concreto, fue reconocida, no por presunta, sino porque había un acervo probatorio contundente que demostraba el retardo y el defecto en la prestación de las asistencias alimentarias y médicas por parte del mencionado órgano estatal.

A pesar de lo anterior, en Sentencia del 30 de agosto de 2018, el Consejo de Estado sostuvo que el régimen general de responsabilidad frente a las PPL y sus bienes es el de la responsabilidad objetiva basada en el concepto de relaciones de especial sujeción. Sin embargo, afirma que ello no impide condenar al Estado por una falla probada, para descartar con ello cualquier posibilidad de causa extraña.

Adicionalmente, en forma más reciente, el Consejo de Estado, en Sentencia del 4 de marzo de 2019, estableció que, frente los daños que sufren las PPL, procede la responsabilidad patrimonial objetiva, basada tanto en el título de imputación del daño especial como en el concepto de relaciones de especial sujeción y sin necesidad de entrar en los terrenos de la falla del servicio. Asimismo, advierte que, para que el Estado pueda invocar una causa extraña, debe probarla plenamente atendiendo a las particulares circunstancias del caso concreto.

Finalmente, vale la pena traer a colación una providencia paradigmática que demuestra cómo, también, la jurisdicción contencioso administrativa ha empleado la existencia del estado de cosas inconstitucional como argumento para abstenerse de condenar al INPEC por la violación de los derechos de las PPL. Así, el Consejo de Estado, en Sentencia del 3 de octubre de 2019 (2014-00186), al resolver una acción de grupo, determinó que, aunque el INPEC era responsable por el "daño a los bienes y derechos constitucional y convencionalmente protegidos causado a los internos del Establecimiento Penitenciario de Mediana Seguridad y C. de Sincelejo (La Vega)”, no por ello había lugar a una condena indemnizatoria.

Así las cosas, la circunstancia de que el único daño acreditado en el presente caso se encuentre circunscrito a la reclamación de facetas esenciales del derecho de la dignidad humana de los internos Establecimiento Penitenciario de Mediana Seguridad y C. de Sincelejo (La Vega), conduce a que la Sala concluya que las medidas dictadas por la Corte Constitucional y por la Sección Quinta del Consejo de Estado sean suficientes para la satisfacción progresiva de dicho propósito. Se advierte que no resulta procedente ninguna indemnización pecuniaria, puesto que no por el hecho de las dificultades en 
el seguimiento y cumplimiento de las medidas contenidas en las órdenes dictadas por la Corte Constitucional, resulta dable concluir que estas sean insuficientes. Para la Sala aceptar la excepcionalidad de la indemnización, solo sería dable si se demostrara la indolencia e indiferencia del Estado en la superación de un ECI en el que precisamente se ocasionan los daños en cuestión. (Consejo de Estado, Sentencia del 3 de octubre de 2019).

De esta manera, el Alto Tribunal, y también los jueces administrativos ${ }^{7}$, han determinado que las condiciones infrahumanitarias en que viven las PPL y que han sido reiteradas en el ECI, por sí solas y aun si causan un daño concreto, no por ello dan lugar a una condena en perjuicios.

Con todo lo dicho, cabe hacerse la siguiente pregunta vinculada, directamente, con nuestro objeto de investigación: ¿cómo se puede aplicar el sistema de responsabilidad que se ha expuesto en este capítulo para resolver los eventuales casos en que las PPL se afecten en su salud o pierdan la vida por la COVID-19? Algunas respuestas aproximativas las expondremos a continuación.

De acuerdo con los estudios epidemiológicos referidos en la primera sección de este escrito, la probabilidad de que las personas se contagien con la COVID-19 se incrementa ostensiblemente por tres factores: por estar en sitios cerrados, con poca ventilación y con aglomeración de personas. Dichos factores se cumplen, evidentemente, en cualquier centro penitenciario y carcelario de Colombia, así haya o no de por medio el problema del hacinamiento reconocido y que, en todo caso, se ha visto reducido significativamente con ocasión de la pandemia $^{8}$. Ello implica, entonces, que las probabilidades de contagio con la COVID-19 para parte de las PPL, en cualquier caso, resultan inevitablemente altas y, en consecuencia, alcanzar estándares satisfactorios en la capacidad de los establecimientos penitenciarios y carcelarios no parece reducir, de forma considerable, las probabilidades de contagio. Por tanto, no pareciera razonable que el solo hecho de contraer la COVID-19 sea imputable al Estado.

Lo anterior tampoco significa que, en estos casos, se deba optar por una total irresponsabilidad del Estado colombiano frente a las PPL que lleguen a

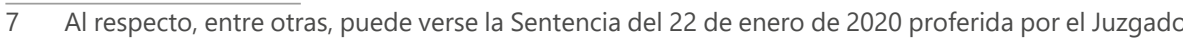
Sexto Administrativo Oral del Circuito de Medellín (Exp. 2018-00125).

8 Recordemos, como se explicó en la segunda sección de este escrito, que la Corte Constitucional ha dejado en claro que las condiciones de hacinamiento y el estado de cosas inconstitucional no generan, en favor de las PPL, el derecho a ser excarceladas.
} 
padecer la COVID-19. Como el contagio de estas personas es difícil de controlar, consideramos que el Estado podría ser responsable, bajo una falla del servicio probada, cuando este no reaccione adecuadamente en el cumplimiento de sus deberes de asistencia médica y clínica de las PPL que, en concreto, resulten contagiadas. Si se prueba el incumplimiento de dichos deberes y ello genera daños antijurídicos, el Estado deberá responder patrimonialmente, pero, si el Estado demuestra la diligencia exigida en el tratamiento médico o, incluso, que el contagio de la COVID-19, por lo dicho, es una causa extraña, deberá eximirse de responsabilidad.

A pesar de lo dicho, en el ámbito de la responsabilidad subjetiva (falla en el servicio probada), un presupuesto para poder eximirse por razones de causa extraña es haber sido diligente. Por tanto, como afirma Tamayo (2007), una vez se encuentra probada la culpa, no es dable acreditar una causa extraña. Esto, en el tema bajo estudio, implicaría afirmar que, si una PPL muere por COVID-19 o le quedan secuelas, y se demuestra que, en su atención, se incumplieron los deberes de asistencia médica, no podría el Estado eximirse de responsabilidad.

Esta tesis defendida por Tamayo (2007) podría ponerse a prueba sobre otra hipótesis y es que, de entrada, el hacinamiento ya es una culpa del Estado que impediría alegar el contagio con la COVID-19 como causa extraña. Sin embargo, consideramos que esta postura, en la jurisprudencia reciente del Consejo de Estado, parece no tener acogida, puesto que, por el contrario, el ECI ha sido empleado como argumento para evitar condenas indemnizatorias a cargo del INPEC, pues se considera que el trámite y la solución a las condiciones infrahumanitarias en que viven las PPL debe darse en el marco de la jurisdicción constitucional y no en el marco de la jurisdicción contencioso administrativa.

Finalmente, algunos podrían pensar que, frente a la crisis generada por la COVID-19, se debería aplicar un régimen objetivo de responsabilidad en favor de las PPL que se contagien, porque ellas están en una especial relación de sujeción con el Estado. Particularmente, consideramos que ello es irrelevante: primero, porque si la COVID-19 se puede tratar como una causa extraña, entonces, en estos casos, el Estado nunca respondería por el solo hecho del contagio; $y$, segundo, porque si se considera que ella es un asunto imputable al Estado (y, por lo tanto, no una causa extraña), este estaría llamado a asumir como carga una pandemia inédita en la historia reciente y en cuya ocurrencia no tuvo materialmente ninguna incidencia al tratarse de un hecho imprevisible e irresistible que sobrepasa, incluso, su ámbito de competencia territorial. 


\section{Conclusiones}

Las condiciones infrahumanitarias en las que, de forma general, sistemática y estructural se encuentran los establecimientos de reclusión en Colombia son inaceptables y alarmantes.

El ECI le ha permitido a la Corte Constitucional, con diferentes énfasis, llamar la atención sobre las afectaciones que sufren, en sus derechos, las PPL. En 1998, con la Sentencia T-153, el Tribunal Constitucional enfatizó en las condiciones infraestructurales de los establecimientos penitenciarios y carcelarios. En 2013 y 2015, con las sentencias T-388 y T-762, la Corte Constitucional fijó el acento en la política criminal del Estado colombiano. Así, desde una perspectiva crítica, consideramos que la COVID-19 ha puesto de presente la necesidad de gestionar, en el ámbito de la jurisdicción constitucional, los aspectos coyunturales de la crisis penitenciaria y carcelaria, relacionados con las condiciones de infraestructura, sin perder de vista las causas estructurales de la crisis permanente. En este sentido, y asumiendo un rol activo, la Corte Constitucional podría redefinir el alcance del estado de cosas inconstitucional y decantarse por un seguimiento minucioso sobre la eficacia de las políticas penitenciaria y carcelaria en Colombia. Volver de nuevo la vista sobre las condiciones de infraestructura que son responsabilidad directa del Gobierno Nacional y de los entes territoriales, a diferencia de las discusiones político criminales que conciernen, principalmente, al Congreso de la República; podría tener efectos concretos y mesurables en las circunstancias vitales de las PPL.

En todo caso, es importante reconocer que la Corte Constitucional, recientemente, en su tarea de seguimiento al ECI, le ha exigido al Gobierno nacional la adopción de medidas idóneas, necesarias y proporcionales para mitigar los efectos de la pandemia en las prisiones. Este es un giro notable en la estrategia de seguimiento que el Tribunal Constitucional había emprendido con ocasión de las sentencias de 2013 y 2015, pues en ellas, fundamentalmente, se le había delegado al ministerio público y a los jueces de instancia la gestión del seguimiento a las órdenes impartidas.

En este orden de ideas, conviene destacar que el hacinamiento carcelario, tantas veces denunciado en el marco del ECI, es un factor determinante, aunque concurrente con otros factores de riesgo, para la propagación de la COVID-19 entre las PPL. Las particulares condiciones inherentes a los establecimientos de prisión hacen que, difícilmente, los protocolos de prevención puedan 
ser efectivos para evitar que un número significativo de PPL terminen contagiadas por la COVID-19. De esta manera, si bien el hacinamiento eleva las probabilidades de contagio y constituye un riesgo para la integridad personal, la salud y la vida de las PPL, debemos reconocer, en términos realistas, una conclusión adicional: aun si se llevase a las prisiones a niveles satisfactorios en términos de capacidad de cupos, ello no incidiría, significativamente, en la reducción de las posibilidades contagio de la COVID-19.

De esta manera, aunque celebramos que, en tan solo pocos meses, el indicador nacional de hacinamiento se ha reducido en casi 30 puntos porcentuales como reacción a la situación de emergencia generada por la pandemia; pasando de 51,5 \% en marzo de 2020, a 21,7\% en octubre de 2020 (INPEC, 2020b), ello, no obstante, no impedirá que la COVID-19 se propague en los establecimientos penitenciarios y carcelarios, como viene ocurriendo, en general, en todo el país. La pandemia es un hecho imprevisible e irresistible, al punto tal que motivó la declaratoria de un estado de emergencia. Así las cosas, las prisiones, con o sin hacinamiento, como lugares encerrados, aglomerados y con ventilación reducida que son (ver Cuadro 1), reúnen las tres características propicias para la propagación de esta enfermedad.

Ello cobra relevancia para analizar la responsabilidad patrimonial del Estado colombiano frente a la violación de los derechos de las PPL. Esta materia ha generado posiciones divergentes en la jurisprudencia del Consejo de Estado. En ocasiones se ha analizado la responsabilidad estatal en este punto como un problema de falla en el servicio (probada o presunta) y, en otras, como un problema jurídico concerniente al daño especial y a las relaciones de especial sujeción. Quizá una de las razones de esta variabilidad es, como lo afirma el propio Consejo de Estado, que, en el caso concreto, el fallador puede, según las circunstancias, elegir el título de imputación que estime adecuado para decidir.

En términos generales, cualquiera que sea la posición que se asuma en relación con la naturaleza del régimen aplicable a la responsabilidad estatal por la violación de los derechos de las PPL, bien sea que se adopte un régimen subjetivo de falla en el servicio (probada o presunta) o un régimen objetivo de daño especial (propio de las relaciones de especial sujeción), consideramos que la jurisprudencia debería decantarse hacia criterios flexibles que permitan evaluar, razonablemente, la responsabilidad concreta del Estado colombiano.

Así las cosas, defendimos, como tesis, que el Estado no debe ser declarado responsable por el solo hecho de que una PPL contraiga la COVID-19, pues 
se trata de una causa extraña, un hecho irresistible e imprevisible que rompe el nexo causal del daño. De este modo, ni siquiera una reducción significativa de los indicadores de hacinamiento, a través de una excarcelación que incluso sea más amplia que la propiciada por el Decreto 546 de 2020 , tendría efectos considerables en términos preventivos. No podemos olvidar, en esta dirección, que la misma Corte Constitucional ha expresado que las condiciones infrahumanitarias de privación de la libertad no otorgan a las PPL el derecho a ser excarceladas. Igualmente, en esta vía, cobran relevancia los pronunciamientos recientes del Consejo de Estado, en los que se ha remarcado que, si bien el INPEC es responsable por transgredir el derecho a la dignidad humana de las PPL debido a las condiciones de hacinamiento en que estas se encuentran, no por ello habrá lugar a condenas indemnizatorias, en tanto que este asunto viene siendo atendido, progresivamente, en el marco del ECI.

Ahora bien, lo anterior no implica afirmar que el Estado deba exonerarse de toda responsabilidad. A nuestro juicio, como lo expusimos, la eventual responsabilidad del Estado colombiano por las afectaciones que sufran las PPL que contraigan la COVID-19 debería discutirse bajo la lógica de la falla en el servicio probada. Este es un escenario particularmente relevante para analizar aquellos casos en los que resulte defectuosa la atención médica y la respuesta sanitaria, por parte de las autoridades estatales, frente al contagio de una PPL.

\section{Referencias}

Aguirre, C. (2009). Cárcel y sociedad en América Latina: 1800 - 1940. En E. Kigman, Historia social urbana. Espacios y fujos (pp. 209 - 252). Quito: Flacso.

Ariza, L. (2000). La realidad contra el texto: una aproximación al estado de cosas inconstitucional. Tutela, 967-978.

Ariza, L. (2013). The Economic and Social Rights of Prisoners and Constitutional Court Intervention in the Penitentiary System in Colombia. En D. Bonilla, Constitutionalism of the Global South: The Activist Tribunals of India, South Africa, and Colombia (págs. 129-162). New York: Cambridge University Press.

Ariza, L. J., y Iturralde, M. (2011). Los muros de la infamia. Prisiones en Colombia y en América Latina. Bogotá D.C.: Uniandes.

Arrieta-Burgos, E. (2017). El sistema penitenciario y carcelario en Colombia: continuidades y discontinuidades foucaultianas. En A. Ruiz, y D. Rincón, Michel Foucault: discurso y poder (págs. 197-234). Medellín: Universidad Pontificia Bolivariana.

Arrieta-Burgos, E., y Duque-Pedroza, A. (2018). Una crítica a la crítica en contra del funcionalismo penal sistémico. Revista de la Facultad de Derecho y Ciencias Políticas, 48 (128), pp. 13-47. 
Arrieta-Burgos, E. (2019). Derechos sociales y proporcionalidad: aproximaciones conceptuales y metodológicas a partir de la jurisprudencia constitucional colombiana. En VV.AA., Estado social y derechos fundamentales en tiempos de retroceso (págs. 135-162). Sevilla: Punto Rojo.

Bernal, C. (2018). Los derechos constitucionales sociales en América Latina Bogotá. En C. Bernal, Derechos, cambio constitucional y teoría jurídica (págs. 169-194). Bogotá: Universidad Externado de Colombia.

Beuchot, M. (2000). Tratado de hermenéutica analógica. Hacia un nuevo modelo de interpretación (2. ${ }^{\circ}$ ed.). México: Universidad Nacional Autónoma de México/Itaca.

Bryman, A. (2012). Social Research Methods. Oxford and New York: Oxford University Press.

Carranza, E. (2009). Cárcel y justicia penal en América Latina y el Caribe. México D.F.: Siglo Veintiuno Editores.

Copi, I., Cohen, C., y Rodych, V. (2018). Introduction to Logic. New York: Routledge.

Courtis, C. (2006). El juego de los juristas. Ensayo de caracterización de la investigación dogmática. En C. Courtis, Observar la ley: ensayos sobre metodología de la investigación jurídica (págs. 105-156). Madrid: Trotta.

Curtis, E., Comiskey, C., y Dempsey, O. (2016). Importance and Use of Correlational Research. Nurse Researcher, 23(6), pp. 20-25.

Duque-Pedroza, A., y Solano, H. (2020). Funcionalismo sistémico y reintegración social. En A. Ruiz, A. Valderrama, y A. Galindo, Justicia, memorial, integración. Debates teóricos y experiencias en el marco de las instituciones sociales (págs. 49-74). Medellín: Universidad Pontificia Bolivariana.

El Espectador. (2020a - 12 de junio). COVID-19 en las cárceles: hay 1472 casos, 1872 recuperados $y$ ocho muertos. . Obtenido de https://www.elespectador.com/ coronavirus/covid-19-en-las-carceles-hay-1065-casos-16-recuperados-y-cuatromuertes-articulo-915830/

El Espectador. (2020b - 18 de noviembre). Las cuentas del Inpec tras ocho meses de pandemia en las cárceles. Obtenido de https://www.elespectador.com/noticias/ judicial/las-cuentas-del-inpec-tras-ocho-meses-de-pandemia-en-las-carceles/

El Tiempo. (9 de julio de 2020). Hacinamiento carcelario está en su punto más bajo desde el 2011. Obtenido de https://www.eltiempo.com/justicia/servicios/sereduce-hacinamiento-carcelario-por-el-coronavirus-al-punto-mas-bajo-en-10anos-515974

Foucault, M. (1975). Surveiller et Punir: Naissance de la prison. Paris: Gallimard.

Foucault, M. (2013). La société punitive. Cours au Collège de France. 1972 - 1973. Paris: EHESS/Gallimard/Seuil.

Foucault, M. (2015). Théories et institutions pénales. Cours au Collège de France. 1971 1972. Paris: EHESS/Gallimard/Seuil.

Garland, D. (1987). Punishment and Welfare. A History of Penal Strategies. England: Ashgate.

Garland, D. (2005). La cultura del control. Crimen y orden social en la sociedad contemporánea. (M. Sozzo, Trad.) Barcelona: Gedisa.

Gómez, A., y Arrieta-Burgos, E. (2018). La responsabilidad del Estado colombiano por la violación de los derechos de las personas privadas de la libertad. En O. Bravo, Perspectivas multidisciplinarias sobre las cárceles Una aproximación desde Colombia y América Latina (págs. 55-97). Cali: ICESI. 
Guastini, R. (2011). Distinguiendo. (J. Ferrer i Beltrán, Trad.) Barcelona: Gedisa.

Hinestrosa, F. (2007). Tratado de las obligaciones. Concepto, estructura, vicisitudes. Tomo I. Bogotá: Universidad Externado de Colombia.

Institute for Crime y Justice Policy Research - Birkbeck University of London. (2020). International News and Guidance on COVID-19 and prisons. Obtenido de World Prison Brief: International news and guidance on COVID-19 and prisons AGREGAR EL URL

Instituto Nacional Penitenciario y Carcelario INPEC. (2020a). Guía de orientación para prevención y manejo de casos COVID 19. Obtenido de Política Criminal: http://www.politicacriminal.gov.co/Portals/0/autos/Respuesta\%20Auto\%20 24\%20de\%20marzo\%20de\%202020/7.\%202020IE0057256\%20Guia\%20de\%20 orientaci\%C3\%B3n\%20para\%20prevenci\%C3\%B3n\%20y\%20manejo\%20de\%20 casos\%20COVID\%2019.pdf

Instituto Nacional Penitenciario y Carcelario INPEC. (2020b). Tableros estadísticos. Población intramural. Noviembre 20 de 2020. Obtenido de http://200.91.226.18:8080/ jasperserver-pro/flow.html?_flowld=dashboardRuntimeFlow\&dashboardResource $=/$ public/DEV/dashboards/Dash_Poblacion_Intramural\&j_username=inpec_user\&j_ password=inpec

Instituto Nacional Penitenciario y Carcelario INPEC. (2020c). Situación actual coronavirus (COVID-19). Establecimientos carcelarios del orden nacional. Noviembre 20 de 2020. Obtenido de https://www.inpec.gov.co/web/guest/covid-19-establecimientos-inpec Instituto Nacional Penitenciario y Carcelario INPEC. (2020d). Series históricas. Noviembre 20 de 2020. Obtenido de https://inpec.gov.co/en/web/guest/estadistica/ estadisticas/-/document_library/3pVdHSI1UBFX/view/960615

Instituto Nacional Penitenciario y Carcelario INPEC. (2020e). Informe estadístico N. ${ }^{\circ}$ 10. Octubre de 2020. Población privada de la liberta -INPECd. Noviembre 20 de 2020. Obtenido de https://www.inpec.gov.co/en/web/guest/estadisticas/-/ document_library/TWBuJQCWH6KV/view_file/1175692?_com_liferay_ document_library_web_portlet_DLPortlet_INSTANCE_TWBuJQCWH6KV_ redirect=https\%3A\%2F\%2Fwww.inpec.gov.co\%2Fen\%2Fweb\%2Fguest\%2Festad isticas\%2F-\%2Fdocument_library\%2FTWBuJQCWH6KV\%2Fview\%2F965447\%3F_ com_liferay_document_library_web_portlet_DLPortlet_INSTANCE_ TWBuJQCWH6KV_redirect\%3Dhttps\%253A\%252F\%252Fwww.inpec.gov.co \%252Fen\%252Fweb\%252Fguest\%252Festadisticas\%252F-\%252Fdocument_ library\%252FTWBuJQCWH6KV\%252Fview\%252F49294

Instituto Nacional de Salud. (16 de octubre de 2020). Covid-19 en Colombia. Obtenido de https://www.ins.gov.co/Noticias/Paginas/Coronavirus.aspx

Johnson, B. (2001). Toward a New Classification of Nonexperimental Quantitative Research. Educational Researcher, 30(2), pp. 3-13.

Jones, L., y Tulloch, O. (Mayo de 2020). COVID-19: Why Are Prisons a Particular Risk, and What Can Be Done to Mitigate this? Obtenido de Institute of Development Studies: https://opendocs.ids.ac.uk/opendocs/handle/20.500.12413/15285

Li, C. e. (2020). Perinatal Transmission of COVID-19 Associated SARS-CoV-2: Should We Worry? Oxford University Press, pp. 1-10.

Liebrenz, M., Bhugra, D., Buadze, A., y Schleifer, R. (2020). Caring for Persons in Detention Suffering with Mental Illness during the Covid-19 Outbreak. Forensic Science International. Mind and Law, 1. Forensic Science International: Mind and Law, pp.1-2. 
López, D. (2011). El derecho de los jueces. Bogotá: Legis.

Márquez-Estrada, J. (2013). Estado punitivo y control criminal. Cárceles, prisiones y penitenciarías en el Siglo XIX. Revista Criminalidad, 55 (1), pp. 99 - 112.

Metall, P., y Youngers, C. (2010). Sistemas sobrecargados. Leyes de drogas y cárceles en América Latina. Ámsterdam/Washington: Transnational Institute.

Ministerio de Justicia de Colombia. (2020a, 25 de junio). Politicacriminal.gov.co. Obtenido de https://politicacriminal.minjusticia.gov.co/PoliticaCriminalWebSite/ Template. aspx? Paginald $=184$

Ministerio de Justicia de Colombia. (2020b). Respuesta al auto de 24 de marzo de la Corte Constitucional. Obtenido de Política Criminal. Obtenido de: http://www.politicacriminal. gov.co/Portals/0/autos/Respuesta\%20Auto\%2024\%20de\%20marzo\%20de\%20 2020/1.\%20Respuesta\%20Auto\%20CC\%20de\%2024\%20de\%20marzo.pdf

Ministerio de Salud y Protección Social. (2020a). Resolución 843 del 26 de mayo de 2020, por medio de la cual se adopta el protocolo de bioseguridad para el manejo y control del riesgo del coronavirus - COVID-19 en establecimientos penitenciarios y carcelarios. Obtenido de: https://www.minsalud.gov.co/Normatividad_Nuevo/ Resoluci\%C3\%B3n\%20No.\%20843\%20de\%202020.pdf

Ministerio de Salud y Protección Social .(2020b). Lineamientos para control, prevención y manejo de casos por COVID-19 para la población privada de la libertad-PPL en Colombia. Obtenido de: https://www.minsalud.gov.co/Ministerio/Institucional/ Procesos\%20y\%20procedimientos/GIPS10.pdf

Montoya-Barthelemy, A., Lee, C. D., Cundiff, D., y Smith, E. (2020). COVID-19 and the Correctional Environment: The American Prison as a Focal Point for Public Health. American Journal of Preventive Medicine, VOL. Y NRO., pp. 888-891.

Morin, E., y Le Moigne, J. (1999). L'intelligence de la complexité. Paris: L'Harmattan.

Ospina, G. (2018). Régimen general de las obligaciones. Bogotá: Temis.

Prieto, R. (2005). Apuntes de teoría del derecho. Madrid: Trotta.

Read, S., y Wild, S. (25 de junio de 2020). What are the Risks of COVID-19 Infection in Pregnant Women? Obtenido de https://www.thelancet.com/action/ showPdf?pii=S0140-6736\%2820\%2930365-2

Richardson et al. (2020). Presenting Characteristics, Comorbidities, and Outcomes Among 5700 Patients Hospitalized With COVID-19 in the New York City Area. JAMA, VOL. y NRO., pp. 2052-2059.

Rodríguez, L. (1992). Panorama de las alternativas a la prisión en América Latina. En E. Carranzas, Sistemas penitenciarios y alternativas a la prisión en América Latina y el Caribe. Buenos Aires: Depalma.

Ruiz, W. (2013). Responsabilidad del Estado y sus regímenes. Bogotá: ECOE Ediciones.

Santofimio, J. (2003). Tratado de derecho administrativo. Tomo VI. Derecho de víctimas y responsabilidad del estado. Bogotá: Universidad Externado de Colombia.

Sociedad de Criminología Latinoamericana y Centro de Estudios Latinoamericanos sobre Inseguridad y Violencia UNTREF - CELIV. (2020). The Effects of Coronavirus in Prisons in Latin America. Obtenido de International Corrections y Prison Asocciation: https://icpa.org/wp-content/uploads/2020/06/The-Effects-of-Coronavirus-inLatin-America-EN.pdf

Solano, H., Duque-Pedroza, A., Díez, M., Arrieta-Burgos, E., Estrada, S., y Monsalve, J. (2019). Temas de derecho penal parte general. Teoría general del derecho penal. Medellín: Universidad Pontificia Bolivariana. 
Tamayo, J. (2007). Tratado de responsabilidad civil. Tomos I y II. Bogotá: Legis. (2018). La responsabilidad del Estado: el daño antijurídico (Constitución Política, art. 90), el riesgo excepcional y las actividades peligrosas. Cali: Editorial Universidad de Cali - USC.

World Health Organization. (25 de junio de 2020). Population-based age-stratified seroepidemiological investigation protocol for coronavirus 2019 (COVID-19) infection. Obtenido de https://apps.who.int/iris/bitstream/handle/10665/332188/ WHO-2019-nCoV-Seroepidemiology-2020.2-eng.pdf

Wurcel, A. G., Dauria, E., Zaller, N., Nijhawan, A., Beckwith, C., Nowotny, K. y BrinkleyRubinstein, L. (2020). Spotlight on jails: COVID-19 Mitigation Policies Needed Now. Clinical Infectious Diseases. Clinical Infectious Diseases,VOL., Nro., pp. 1-2.

Yáñez, D. (2014). Las órdenes de la Corte Constitucional: su papel y límites en la formulación de políticas públicas. Estudios de Derecho, 71(157), pp. 235-268. Recuperado a partir de https://revistas.udea.edu.co/index.php/red/article/ view/21664

Zhou et al. (2020). Clinical Course and Risk Factors for Mortality of Adult Inpatients with COVID-19 in Wuhan, China: a Retrospective Cohort Study. The Lancet, 1054-1062.

\section{Sentencias}

Corte Constitucional de Colombia. (1998, 28 de abril). Sentencia T - 153 de 1998 (Eduardo Cifuentes Muñoz, M.P.). Recuperado de: https://www.corteconstitucional. gov.co/relatoria/1998/t-153-98.htm

Corte Constitucional de Colombia. (2004, 22 de enero). Sentencia T-025 de 2004 (Manuel José Cepeda Espinosa, M.P.). Recuperado de: https://www.corteconstitucional.gov. co/relatoria/2004/t-025-04.htm

Corte Constitucional de Colombia. (2008, 7 de noviembre). Auto 303 de 2008 (Manuel José Cepeda Espinosa, M.P.). Recuperado de: https://www.corteconstitucional.gov. co/relatoria/autos/2008/A303-08.htm

Corte Constitucional de Colombia. (2011, 4 de marzo). Auto 041 de 2011 (María Victoria Calle Correa, M.P.). Recuperado de: https://www.corteconstitucional.gov. co/relatoria/autos/2011/A041-11.htm

Corte Constitucional de Colombia. (2016, 17 de agosto). Auto 368 de 2016 (Gloria Stella Ortiz Delgado M.P.). Recuperado: https://www.corteconstitucional.gov.co/ relatoria/autos/2016/A368-16.htm

Corte Constitucional de Colombia. (2016, 23 de agosto). Auto 373 de 2016 (Luis Ernesto Vargas Silva, M.P.). Recuperado de: https://www.corteconstitucional.gov. co/relatoria/autos/2016/A373-16.htm

Corte Constitucional de Colombia. (2013, 23 de agosto). Sentencia T - 388 de 2013 (María Victoria Calle Correa, M.P.). Recuperado de: https://www.corteconstitucional. gov.co/relatoria/2013/t-388-13.htm

Corte Constitucional de Colombia. (2015, 27 de enero). Sentencia T - 762 de 2015 (Gloria Stella Ortiz Delgado, M.P.). Recuperado de: https://www.corteconstitucional. gov.co/relatoria/2015/t-762-15.htm

Corte Constitucional de Colombia. (2015, 18 de diciembre). Sentencia T-774 de 2015 (Luis Ernesto Vargas Silva, M.P.). Recuperado de: https://www.corteconstitucional. gov.co/relatoria/2015/t-774-15.htm 
Consejo de Estado de Colombia. (1991, 25 de octubre). Sentencia del 25 de octubre de 1991 con número de radicación 6465 (Carlos Betancur Jaramillo, C.P.). Recuperado de: file:///C:/Users/users_sf314/Downloads/CE-SEC3-EXP1991-N6465.html

Consejo de Estado de Colombia. (1993, 4 de noviembre). Sentencia del 4 de noviembre de 1993 con número de radicación 8335 (Julio Uribe Acosta, C.P). Recuperado de: file:///C:/Users/users_sf314/Downloads/CE-SEC3-EXP1993-N8335.html

Consejo de Estado de Colombia. (2004, 20 de mayo). Sentencia del 20 de mayo de 2004 con número de radicación 22662 (Ricardo Hoyos Duque, C.P). Recuperado de: https://relatorestematicos.uniandes.edu.co/images/stories/relatorias/PRISIONESOCT2011/JURIS.NACIONAL/CONSEJO.ESTADO/2004.mayo20.pdf

Consejo de Estado de Colombia. (2006, 27 de abril). Sentencia del 27 de abril de 2006 con número de radicación 20125 (Alier Hernández, C.P.). Recuperado de: file:///C:/ Users/users_sf314/Downloads/76001-23-31-000-1998-00135-01(20125).html

Consejo de Estado de Colombia. (2008, 20 de febrero). Sentencia del 20 de febrero de 2008 con número de radicación 16996. (Enrique Gil Botero, C.P.). Recuperado de: file:///C:/ Users/users_sf314/Downloads/76001-23-25-000-1996-04058-01(16996).html

Consejo de Estado de Colombia. (2009, 11 de febrero). Sentencia del 11 de febrero de 2009 con número de radicación 16750 (Myriam Guerrero, C.P.). Recuperado de: https://www.redjurista.com/Documents/consejo_de_estado,_seccion_tercera_e._ no._16750_de_2009.aspx\#/

Consejo de Estado de Colombia. (2010, 9 de junio). Sentencia del 9 de junio de 2010 con número de radicación 19849 (Enrique Gil Botero, C.P.). Recuperado de: file:///C:/ Users/users_sf314/Downloads/19001-23-31-000-1997-08006-01(19849).html

Consejo de Estado de Colombia. (2016, 25 de julio). Sentencia del 25 de julio de 2016 con número de radicación 33868 (Jaime Orlando Santofimio Gamboa, C.P). Recuperado de: file:///C:/Users/users_sf314/Downloads/76001-23-31-000-2002-03560-01(33868). html

Consejo de Estado de Colombia. (2017, 18 de mayo). Sentencia del 18 de mayo de 2017 con número de radicación 37497. (Jaime Orlando Santofimio Gamboa, C.P). Recuperado de: file:///C:/Users/users_sf314/Downloa ds/68001-23-31-000-2003-00450-01(37497).html

Consejo de Estado de Colombia. (2018, 2 de mayo). Sentencia del 2 de mayo de 2018 con número de radicación 40557. (Jaime Orlando Santofimio Gamboa, C.P). Recuperado de: file:///C:/Users/users_sf314/ Downloads/54001-23-31-000-1999-00151-01(40557).html

Consejo de Estado de Colombia. (2018, 2 de agosto). Sentencia del 2 de agosto de 2018 connúmero deradicación 46495 (María Adriana Marín, C.P). Recuperado de: file:///C:/ Users/users_sf314/Downloads/41001-23-31-000-2006-00933-01(46495)_1.html

Consejo de Estado de Colombia. (2019, 4 de marzo). Sentencia del 4 de marzo de 2019 con número de radicación 48110. (María Adriana Marín, C.P). Recuperado de: file://C:/Users/users_sf314/Downloads/68001-23-31-000-2010-00597-01(48110). html

Juzgado Sexto Administrativo Oral del Circuito de Medellín. (2020, 22 de enero). Sentencia del 22 de enero de 2020 con radicado 2018-00125. Recuperado de:https://procesos.ramajudicial.gov.co/procesoscs/ConsultaJusticias 21. aspx?Entryld=qwlshSrNf27FeEqo8p1TIFRIb\%2bc\%3d 